\title{
PORT SITE HERNIA: MINOR BUT SEVERE COMPLICATION OF LAPAROSCOPIC CHOLECYSTECTOMY.
}

\footnotetext{
1. MBBS, FCPS

Assistant Professor Surgery

CMC @SMBBMU Larkana.

2. MBBS, FCPS

Medical Officer Surgery

CMC @SMBBMU Larkana.

3. MBBS, FCPS

Senior Registrar Surgery CMC @SMBBMU Larkana.

4. MBBS, FCPS

Professor Surgery

CMC @SMBBMU Larkana.

5. MBBS, MS (General Surgery)

Assistant Professor Surgery

CMC @SMBBMU Larkana.

6. MBBS, FCPS

Associate Professor Anatomy

CMC @SMBBMU Larkana.
}

Correspondence Address:

Dr. Abdul Sattar Abro

Bunglow No.13, Doctors Model

Colony

Behind Chandka Teaching Hospital,

Larkana.

surgeonsattar@gmail.com

Article received on:

$10 / 02 / 2020$

Accepted for publication:

06/05/2020

\begin{abstract}
Ehsanullah Malik ${ }^{1}$, Sania Bhatti ${ }^{2}$, Muharram Ali Abbasi ${ }^{3}$, Yasmeen Bhatti ${ }^{4}$, Abdul Sattar Abro $^{5}$, Shahid Hussain Soomro ${ }^{6}$

ABSTRACT... Laparoscopic cholecystectomy is a gold standard procedure for the management of patients with cholelithiasis with fewer complications but still port site hernia is one of the severe complications if not treated properly may lead adverse result. This usually results from improper closure or infection of the musculoaponeurotic layers of the abdominal wall. The frequency of port site hernia is variable in literature and its association with infection and other co-morbidities is less explored. Objectives: To determine the frequency of port-site hernia after laparoscopic cholecystectomy at a tertiary care hospital Larkana and its association with infection and comorbidities. Study Design: Descriptive Case Series study. Setting: Department of Surgery, Chandka Medical College Teaching Hospital, Larkana. Period: December 2018 to December 2019. Material \& Methods: One hundred forty-eight patients undergoing elective laparoscopic cholecystectomies, were selected for this study. Results: The majority of the patients 79 (53.4\%) were above the age of 35 years. The mean age of the patients was $40.14 \pm 11.40$ years. Females were younger than males. Among them 19 (12.8\%) were males compared to 129 $(87.2 \%)$ females. Mean BMI $\left(\mathrm{kg} / \mathrm{m}^{2}\right)$ of male patients were $25.98 \pm 3.53$ and female patients were $24.80 \pm 3.04$. The mean duration of surgery was $63.72( \pm 18.20)$ minutes, mostly accomplished is within 80 mins $(54.1 \%)$. Out of 148 patients in $5(3.4 \%)$ patients port site hernia was observed. In all these patients wound to get infected and surgery was for a prolonged period. Conclusion: The frequency of port site hernia is low but could be disastrous if the bowel gets obstructed. Using good technique and reducing operative time are effective measures in reducing the port site infection and the port site hernia.
\end{abstract}

Key words: $\quad$ Laparoscopic Cholecystectomy, Operative Time, Port Site Infection, Port Site Hernia.

Article Citation: Malik E, Bhati S, Abbasi MA, Bhatti Y, Abro AS, Soomro SH. Port site hernia: Minor but severe complication of laparoscopic cholecystectomy. Professional Med J 2020; 27(8):1717-1721

DOI: 10.29309/TPMJ/2020.27.08.4558

\section{INTRODUCTION}

Laparoscopic cholecystectomy (LC) has revolutionized intra-abdominal surgery and is now a gold standard for the treatment of symptomatic cholelithiasis. This fact was in part due to the use of small incisions, which produce less wound pain and result in speedy postoperative recovery, but like any other surgical procedure, it is not without complications and one of its serious complications includes port site hernia.

Port site hernia is a type of incisional hernia. Herniation through the port site may result from inadequate closure of the musculoaponeurotic layers of the abdominal wall or wound dehiscence. It usually occurs at the site of a $10 \mathrm{~mm}$ sized port at umbilicus. ${ }^{1}$ Although port site hernia has also been reported at $5 \mathrm{~mm}$ port sites. ${ }^{2}$ In addition to pain, port site hernia can lead to severe complications including bowel obstruction, strangulation and peritonitis. $^{3}$

$P$ ort site hernias have been classification into 4 types. A: Normal stab wound of trocar site, $B$ : early-onset type: Dehiscence of the anterior and posterior fiscal plane and peritoneum $\mathrm{C}$ : Late-onset type: dehiscence of the anterior and posterior facial plane. Peritoneum constitutes hernia sac and $D$, Dehiscence of the whole abdominal wall - the protrusion of intestine, omentum or both. ${ }^{4,5,6}$ 
This study aims to determine the frequency of port site hernia after laparoscopic cholecystectomy as this procedure is the mainstay of surgical practice these days and therefore complications of this procedure must be well known and documented so that these should have avoided or appropriately managed. Further we also try to evaluate its association with co-morbid factors which affect wound healing like diabetes mellitus, smoking and increased BMI.

\section{MATERIAL \& METHODS}

It is a Descriptive case series conducted at Department of Surgery, Chandka Medical College Teaching Hospital, Larkana from December 2018 to December 2019 Non-probability consecutive technique was used.

The sample size was calculated by Open Epi, Version 3, open-source sample size calculator, taking anticipated frequency of port site hernia after laparoscopic cholecystectomy as $4.1 \% .^{7}$ with confidence interval $95 \%$, and absolute precision of $3.2 \%$, the sample size came out to be 148 .

Patients of either gender, age between 18 years and 60 years, underwent laparoscopic cholecystectomy were included in this study. While patients having, post-operative cough, previous laparotomy, and acute cholecystitis were excluded.

A total of 148 patients diagnosed as a case of cholelithiasis were admitted through OPD. Proper history, clinical examination and all relevant investigations were carried out. All patients underwent laparoscopic cholecystectomy under general anaesthesia through 4 standard ports (10mm umbilical port inserted through Hassan's technique and $5 \mathrm{~mm}$ ports inserted under vision). Vicryl was used to close the fascial defect. The details of each patient were recorded in a specially designed proforma. Data analysis was done through SPSS version 21.

\section{RESULTS}

Out of 148 patients of cholelithiasis, who underwent laparoscopic cholecystectomy, 129
$(87.2 \%)$ were females whereas only 19 (12.8\%) were male (Figure-1). Male to female ratio was $1: 6.7$.

The mean age of the patients was $40.14 \pm 11.40$ years. Most of the patients 79 (53.4\%) were above 35 years of age. The mean age of male patients was $45.79 \pm 10.82$ years while the mean age of females was $38.91 \pm 11.23$ (Figure-2).

Mean height of male and female patients were $166.7 \pm 8.6 \mathrm{~cm}$ and $160.1 \pm 5.9 \mathrm{~cm}$ respectively. Mean weight (in Kilograms) of male and female patients were $71.7 \pm 6.2$ and $63.55 \pm 6.95$ respectively. The mean $\mathrm{BMl}$ of male patients were $25.98 \pm 3.53$ and female patients were $24.80 \pm 3.04$.

A total of 12 patients were smokers. 6 out of 129 females (4.6\%) were found to be smokers while 6 out of 19 males were smokers (31.6\%).

15 out of 148 (10.15\%) were diabetic at the time of surgery. Among them only 2 were male. However, the frequency of diabetes among both female and male almost remained constant at $10.1 \%$ and $10.5 \%$ respectively.

Most of the cholecystectomies were accomplished is within 80 mins $(54.1 \%)$ in this study, with a mean duration of surgery was $63.72(+18.20)$ minutes. The mean duration of surgery of male cases $(n=19)$ were $75.53 \pm 19.9$ minutes. This mean was higher than the female counterpart which was $61.98 \pm 17.43$. The difference between the duration of surgery between both gender was statistically significant.

Out of 148 patients, in 5 (3.4\%) patients port site hernia was observed. Time of surgery in all patients who developed port-site hernia was $>60$ minutes and all had acquired port site infection. Overall $7(4.7 \%)$ patients developed wound infection among them 5 (3.4\%) had developed hernia (Table-I). A significant association has been found between port site hernia, duration of surgery and port site infection. However, no significant association has been found between port site hernia and gender, age, BMI, smoking 
or diabetes.

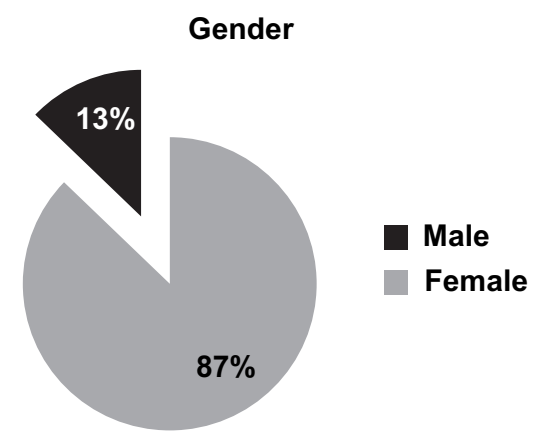

Figure-1. Gender distribution $(n=148)$

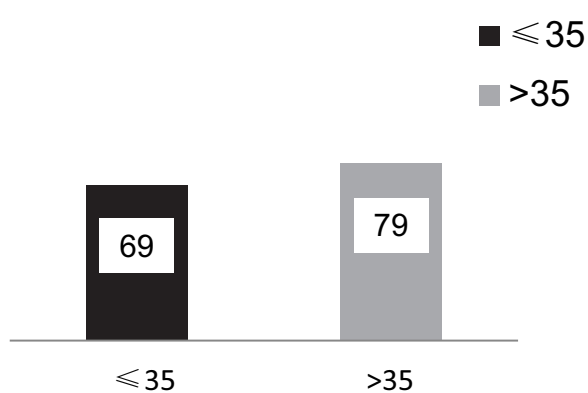

Figure-2. Age distribution $(n=148)$

\begin{tabular}{|c|c|c|}
\hline Time of surgery (min) & Infection & Port site hernia \\
\hline$<60$ & 0 & 0 \\
\hline$>60$ & $7(4.7 \%)$ & $5(3.4 \%)$ \\
\hline \multicolumn{3}{|c|}{ Table 1: Showing relation of time of } \\
surgery with wound infection and port site \\
hernia $(\mathbf{n = 1 4 8 )}$ ) \\
\multicolumn{3}{|c|}{ Mean age $=\mathbf{4 0 . 1 4} \pm 11.40$ years } \\
\hline
\end{tabular}

\section{DISCUSSION}

Laparoscopic cholecystectomy is an established "gold standard" treatment of symptomatic cholelithiasis. It does have countless benefits over open procedures. There is a common myth that laparoscopic procedures are complicationfree. However, the truth is, surgeons do encounter complications like incisional hernia, per operative bleeding, bowel injuries and port site infection with variable frequencies. ${ }^{8}$ Most of them usually present either per-operative or early post-operative course. However, port-site incisional hernia usually presents late, but it has a more serious outcome as there is a serious risk of bowel strangulation because of the small defect. Review of literature revealed that port site hernia almost always occurred at the umbilical site and always after the use of trochar size of $10-12 \mathrm{~mm} .^{9,10}$ However, few authors believed that increasing the size of the incision to retrieve the specimen favours post-operative trochar site hernia (TSH) incidence. ${ }^{7,11}$ Apart from this, port site infection is also one of the cause for hernia, it may be due to spillage of bile during gall bladder extraction. ${ }^{12,13}$

Several studies have been conducted to check the real frequency of port site hernia ranges from low as $0.5 \%{ }^{14}$ to ridiculously high as $22 \% .{ }^{11}$ However the standard acceptable range in literature is 1.61.8. ${ }^{15}$ The result of the current study (i-e port site hernia frequency of $3.4 \%$ ) is higher than the result of Memon et $\mathrm{al}^{16}$, he reported $2.14 \%$ port site hernia after 2 years follow up. In our study $7(4.7 \%)$ patients developed wound infection among them 5 (3.4\%) had developed port site hernia. This Indicates strong correlation of infection with the hernia. Infection may cause weakness of wound and followed by hernia. Various studies have mentioned the association of wound infection with port site hernia. ${ }^{15,17,18,19}$ In our study around $71 \%$ cases of port site hernia were associated with port site infection. Jamil $\mathrm{M}$ et $\mathrm{al}^{20}$ have mentioned $60 \%$ port hernia with an infection while Memon et $\mathrm{al}^{16}$ and Nassar et $\mathrm{al}^{21}$ have described $65.5 \%$ and $31.25 \%$ cases respectively, who developed port site hernia after infection.

Obesity is a well-known risk factor not only for wound infections but also for incisional hernia. Several other factors have also been identified like increase intra-abdominal pressure, and difficult fascial closure ${ }^{22}$ However, we did not find any significant association of these factors with port site hernia. We did not find any relation between $\mathrm{BMI}$ and port site hernia. A similar result has been postulated by Erdas et al. ${ }^{23}$ Bowery et al did find a positive trend of trochar site hernia associated with raised $\mathrm{BMI}$ but this association did reach statically significance. ${ }^{24}$

Diabetes and smoking are also known factors responsible for wound infection and dehiscence, but none of them reported for causative factors for port site hernia. ${ }^{23}$ These findings are similar to our study, as we found no association between diabetes and port site hernia. Similar result has 
been found for smoking.

In our study we noticed that in all patients who developed port site hernia, duration of surgery was prolonged (>60 minutes). In the line of our study, some authors have also mentioned that increased manipulation and increased duration of surgery are factors associated with port site hernia. ${ }^{16,25}$ Overall few studies have been conducted to explore the relation between duration of surgery and port site hernia. This aspect needs more research.

In a nutshell, Port site hernia is a multifactorial disease and mostly related to surgical techniques like large trochar size, poor fascial closing technique and surgical site infection.

\section{CONCLUSION}

In summary, the frequency of port site hernia is comparably low but could be disastrous if the bowel gets obstructed. Using good technique and reducing operative time are effective measures in reducing the port site infection and port site hernia.

Copyright@ 06 May, 2020.

\section{REFERENCES}

1. Bhutta AR, Waheed M, Majid A, Ali SM, Ahmed N, Abid KJ. Port site wound hernias after laparoscopic cholecystectomy. Biomedica. 2004; 20:104-5.

2. Madhavan SM, Potunru VK, Augustine AJ. Bowel herniation through $5 \mathrm{~mm}$ port site: An unusual complication. J Clin Diagn Res. 2016; 10(4):23.

3. Jamil M, Falah SQ, Marwat AA, Soomro MI. Port site hernia: A complication of minimal access surgery. Gomal J Med Sci. 2016; 14: 92-4.

4. Hussain A, Mahmood H, Singhal T, Balakrishnan S, Nicholls J, El-Hasani S. Long term study of port-site incisional hernia after a laparoscopic procedure. JSLS 2009; 13: 346-49.

5. Zhu J, Liu W. Laparoscopic trocar site hernia: A case report and literature review. Int J Clin Exp Med. 2016; 9(1):1-8.

6. Ramesh B, Kurkuri SN, Metgud SB. Laparoscopic 5-mm port site hernia: $A$ rare but preventable complication of laparoscopy. Int J Reprod Contracept Obstet Gynecol. 2016; 5(11):4056-60.
7. Boldo E, de Lucia GP, Aracil JP, Martin F, Escrig J, Martinez D, Miralles JM, Armelles A. Trocar site hernia after laparoscopic ventral hernia repair. Surgical endoscopy. 2007 May 1; 21(5):798-800.

8. Schmedt C-G, Leibel B J, Daubler P, Bittener R. Access related complications an analysis of 4857 consecutive laparoscopic surgeries. Minimal invasive allied technology 2009; 10:23-29.

9. MontzFJ, Holschneider $\mathrm{CH}$, Munro MG. Incisional hernia following laparoscopy: A survey of the American Association of Gynecologic Laparoscopists. The Journal of the American Association of Gynecologic Laparoscopists. 1994 Aug; 1(4, Part 2): S23-4.

10. Boike GM, Miller CE, Spirtos NM, Mercer LJ, Fowler JM, Summitt R, Orr Jr JW. Incisional bowel herniations after operative laparoscopy: A series of nineteen cases and review of the literature. American journal of obstetrics and gynaecology. 1995 Jun 1; 172(6):172633.

11. Kopelman D, Schein M, Assalia A, Hashmonai M. Small bowel obstruction following laparoscopic cholecystectomy: Diagnosis of incisional hernia by computed tomography. Surgical laparoscopy \& endoscopy. 1994 Aug; 4(4):325-6.

12. Taj MN, Iqbal $Y$, Akbar Z. Frequency and prevention of laparoscopic port site infection. J Ayub Med Coll Abbottabad 2012; 24(3-4): 197-199.

13. Khan ANA, Parhar AB, Malik ZI, Qureshi KH. Comparison of infection; Removal of gall bladder with and without bag. Professional Med J 2016; 23(7): 835-839.

14. Helgstrand F, Rosenberg J, Bisgaard T. Trocar site hernia after laparoscopic surgery: A qualitative systematic review. Hernia. 2011 Apr 1; 15(2):113-21.

15. A Tonouchi $\mathrm{H}$, Ohmori $\mathrm{Y}$, Kobayashi M, Kusunoki M. Trocar site hernia. Archives of surgery. 2004 Nov 1; 139(11):1248-56.

16. Memon MR, Arshad S, Rafiq S, Bozdar AG, Shah SQ. Port-site hernia: A serious complication of laparoscopy. Rawal Med J. 2011; 36:14-7.

17. Coda A, Bossotti M, Ferri F, Mattio R, Ramelini G, Poma A. Incisional hernia and fascila defect following laproscopic surgery. Surg Laprosc Endosco Percutan Tech 2000; 10: 34-38.

18. Nervi V, Fersini A, Ambrosi A, Tartaglia N, valentine TP. Umbilical port-site complications in laparoscopic cholecystectomy: The role of topical antibiotic therapy. JSLS 2008; 12; 126-32. 
19. Lablanc F, Champagne BJ, Augestad KM, Stein SL, Marderstein E, Reynolds $\mathrm{HL}$ et al. Single-incision laparoscopic colectomy: Technical aspects, feasibility and expected benefits. Diagn Ther Endosc 2010; 913216.

20. Jamil M, Falah SQ, Marwat AA, Soomro MI. Port site hernia: A complication of minimal access surgery. Gomal J Med Sci 2016; 14:92-4.

21. Nassar AH, Ashkar KA, Rashed AA, Abdulmoneum MG. Laparoscopic cholecystectomy and the umbilicus. Br J Surg 1997; 84:630-3.

22. Cottam DR, Gorecki PJ, Curvelo M, Weltman D, Angus LG, Shaftan G. Preperitoneal herniation into a laparoscopic port site without a fascial defect. Obesity surgery. 2002 Feb 1; 12(1):121-3.
23. Erdas E, Dazzi C, Secchi F, Aresu S, Pitzalis A, Barbarossa M, Garau A, Murgia A, Contu P, Licheri S, Pomata M. Incidence and risk factors for trocar site hernia following laparoscopic cholecystectomy: A long-term follow-up study. Hernia. 2012; 16(4):431-7.

24. Bowrey DJ, Blom D, Crookes PF, Bremner CG, Johansson JL, Lord RV, Hagen JA, De Meester SR, De Meester TR, Peters $\mathrm{JH}$. Risk factors and the prevalence of trocar site herniation after laparoscopic fundoplication. Surgical endoscopy. 2001 Jul 1; 15(7):663-6.

25. Bunting DM. Port site hernia following laparoscopic cholecystectomy. JSLS 2010; 14: 490-97.

\begin{tabular}{|c|l|l|l|}
\hline \multicolumn{3}{|c|}{ AUTHORSHIP AND CONTRIBUTION DECLARATION } \\
\hline Sr. \# & \multicolumn{1}{|c|}{ Author(s) Full Name } & Contribution to the paper & Author(s) Signature \\
\hline 1 & Ehsanullah Malik & 1st Author & \\
\hline 2 & Sania Bhatti & 2nd Author & \\
\hline 4 & Muharram Ali Abbasi & 3rd Author & \\
\hline 5 & Ybdul Sattar Abro & 4th Author & \\
\hline 6 & Shahid Hussain Soomro & 6th Author & \\
\hline
\end{tabular}

